\title{
Treatment of congenital adrenal hyperplasia and Klinefelter Syndrome with central precocious puberty: a case report
}

\author{
Yan $\mathrm{Li}^{1 \wedge}$, Ting Zhang ${ }^{2}$, Pin $\mathrm{Li}^{1}$ \\ ${ }^{1}$ Department of Endocrinology, Shanghai Children's Hospital, Shanghai Jiao Tong University, Shanghai, China; ${ }^{2}$ Department of Gastroenterology, \\ Shanghai Children's Hospital, Shanghai Jiao Tong University, Shanghai, China \\ Correspondence to: Pin Li. Department of Endocrinology, Shanghai Children's Hospital, Shanghai Jiao Tong University, Shanghai 200062, China. \\ Email: lipin21@126.com; Ting Zhang. Department of Gastroenterology, Shanghai Children's Hospital, Shanghai Jiao Tong University, Shanghai \\ 200062, China. Email: zhangt@shchildren.com.cn.
}

\begin{abstract}
The simultaneous occurrence of Klinefelter syndrome (KS) and congenital adrenal hyperplasia $(\mathrm{CAH})$ is extremely rare, as the former causes androgen deficiency, while the latter results in androgen excess. In addition, central precocious puberty (CPP) will occur, which is caused by the activation of the hypothalamic-pituitary-gonadal (HPG) axis by androgens. We present the 7th reported case of simultaneous $\mathrm{KS}$ and CAH in a boy with CPP due to protopathy of CAH. He presented with increased gonadotropin and excessive androgen levels, and was diagnosed with $\mathrm{KS}$ due to his unexpected karyotype analysis results. This is the first reported case of an association between $\mathrm{KS}$ and $\mathrm{CAH}$ to undergo gonadotropin-releasing hormone analog $(\mathrm{GnRHa})$ and recombinant human growth hormone (rhGH) therapy to increase his predicted final height. His predicted adult height was approximately $160 \mathrm{~cm}$ by estimation using the bone age as well as current height, which is much taller than the estimated height before treatment. Although KS may cause hypogonadism, the patient should be administered GnRHa and rhGH therapy if simultaneous CAH, CPP, and KS are present to increase the patient's predicted final height. Excessive androgen levels may mask the symptoms of KS-related hypogonadism during childhood; however, the patient should be made aware of the possibility of hypogonadism developing in the future.
\end{abstract}

Keywords: Congenital adrenal hyperplasia (CAH); Klinefelter syndrome (KS); central precocious puberty (CPP); gonadotropin-releasing hormone analog $(\mathrm{GnRHa})$; case report

Submitted Sep 13, 2021. Accepted for publication Jan 06, 2022.

doi: $10.21037 / \mathrm{tp}-21-442$

View this article at: https://dx.doi.org/10.21037/tp-21-442

\section{Introduction}

Congenital adrenal hyperplasia $(\mathrm{CAH})$ is an autosomal recessive genetic disease caused by the deficiency of an enzyme involved in glucocorticoid biosynthesis (1). Approximately $90 \%$ of CAH cases are caused by 21-hydroxylase deficiency (21-OHD) due to mutations in the CYP21A2 gene. The clinical features may range from mild (non-classical) to severe (classical); the latter can also be classified as either a simple-virilizing or salt-wasting form. The classical, simple-virilizing form of the disease can cause male sexual precocious puberty with bone age advancement and compromised final height. Klinefelter syndrome (KS) is a sex chromosomal disorder characterized by an extra $\mathrm{X}$ chromosome, which results in a 47, XXY karyotype, or in rare cases, $(46, \mathrm{XY}) /(47, \mathrm{XXY})$ mosaicism (2). The hallmark of KS is hypogonadism with decreased levels of testosterone, which causes an increased pituitary secretion of the luteinizing hormone (LH) and follicle stimulating hormone (FSH). This typically occurs during adolescence.

In the present study, we describe the case of a boy

^ ORCID: 0000-0002-2429-6657. 


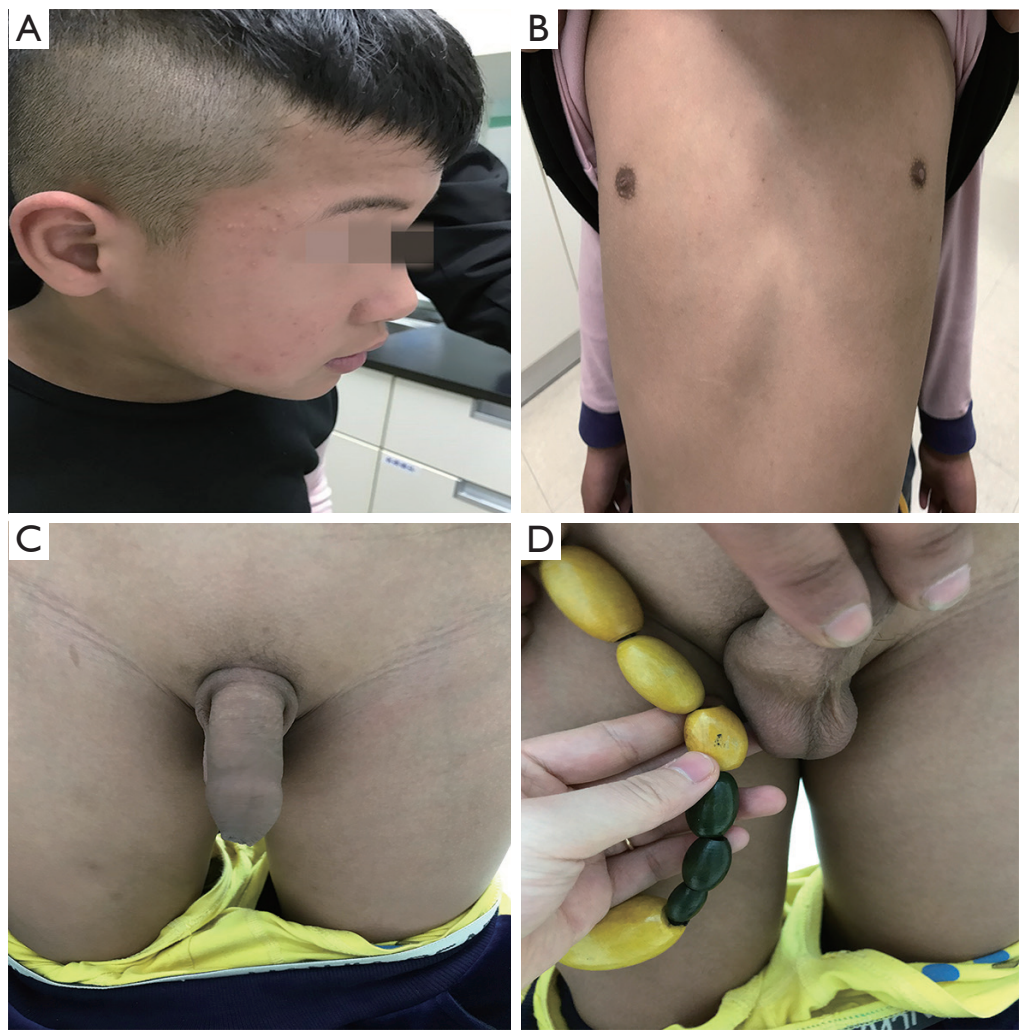

Figure 1 The clinical features of the patient at the first physical examination. (A) The generalized pachylosis and acne on the patient's face. (B) The examination of hyperpigmentation, particularly in the mammary areola. (C,D) The examination of the externalia revealed 4 mL testes and phallic enlargement. These images are published with the patient and his parents' consent.

affected by both KS and CAH (21OHD), and presented the results of treatment for current androgen excess and preventative treatment for androgen insufficiency.

We present the following article in accordance with the CARE reporting checklist (available at https:// tp.amegroups.com/article/view/10.21037/tp-21-442/rc).

\section{Case presentation}

\section{Clinical data}

A 4-year and 6-month-old boy presented to the pediatric outpatient department of the First Affiliated Hospital of Henan University of Chinese Medicine due to penis enlargement over the course of 6 months. He had previously presented with growth acceleration and acne on his face (Figure 1A); however, he did not present with frequent vomiting or other presentations of dehydration during the neonatal period.

Upon examination, he was $130 \mathrm{~cm}$ tall $\left(>97^{\text {th }}\right.$ percentile of boys of Han nationality in the same age group in China) and weighed $31.5 \mathrm{~kg}$. His blood pressure was 97/60 $\mathrm{mmHg}$. Physical examination revealed pachylosis and generalized hyperpigmentation, particularly in the mammary areola (Figure 1B). Examination of the externalia revealed $4 \mathrm{~mL}$ testes, $7 \mathrm{~cm}$ penile length, and Tanner 2 pubic hair (Figure $1 C, 1 D)$. Initial investigation revealed the following values: testosterone, $2.92 \mathrm{ng} / \mathrm{mL}(0-0.25 \mathrm{ng} / \mathrm{mL})$; estradiol, $79 \mathrm{pg} / \mathrm{mL}(20-41 \mathrm{pg} / \mathrm{mL})$; dehydroepiandrosterone sulfate, $21.7 \mathrm{ug} / \mathrm{dL}(60-560 \mathrm{ug} / \mathrm{dL})$; androstenedione, $10 \mathrm{ng} / \mathrm{mL}$ (0.7-3.6 ng/mL), 17a-hydroxyprogesterone (17OHP), $277.6 \mathrm{ng} / \mathrm{mL}(<2.32 \mathrm{ng} / \mathrm{mL})$; progesterone, $17.56 \mathrm{ng} / \mathrm{mL}$ (0.05-1.4 ng/mL); cortisol, $2.8 \mathrm{ug} / \mathrm{dL}(8.7-22.4 \mathrm{ug} / \mathrm{dL})$; and adrenocorticotrophic hormone, $921 \mathrm{pg} / \mathrm{dL}(0-46 \mathrm{pg} / \mathrm{dL})$. His LH and FSH levels were 0.01 and $0.22 \mathrm{mIU} / \mathrm{mL}$, respectively. His human chorionic gonadotropin and electrolyte levels (including serum sodium and serum potassium), thyroid function, and tumor markers, such as alpha fetoprotein and carcinoembryonic antigen levels, were within the normal range. The patient's bone age was 
A

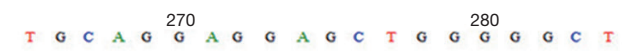

Patient

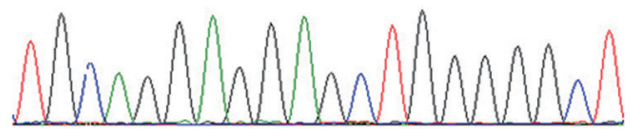

B

Father

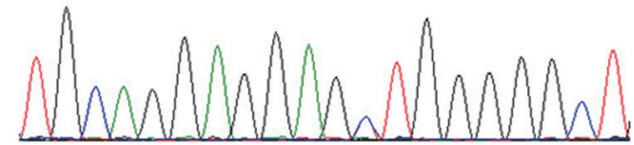

C

Mother
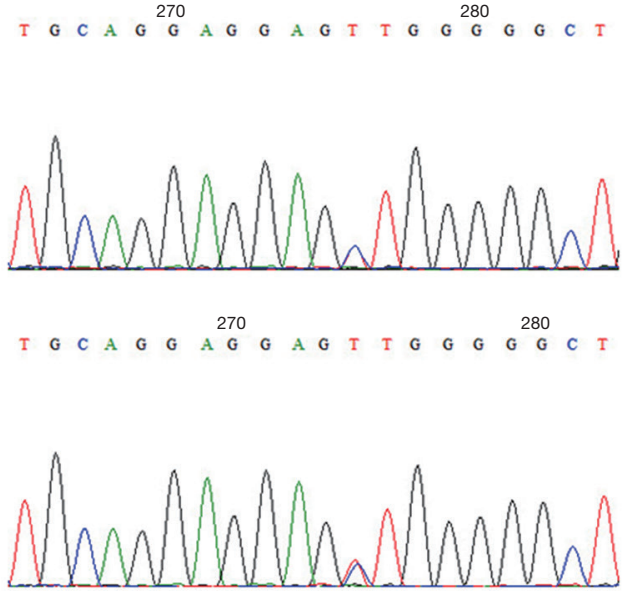
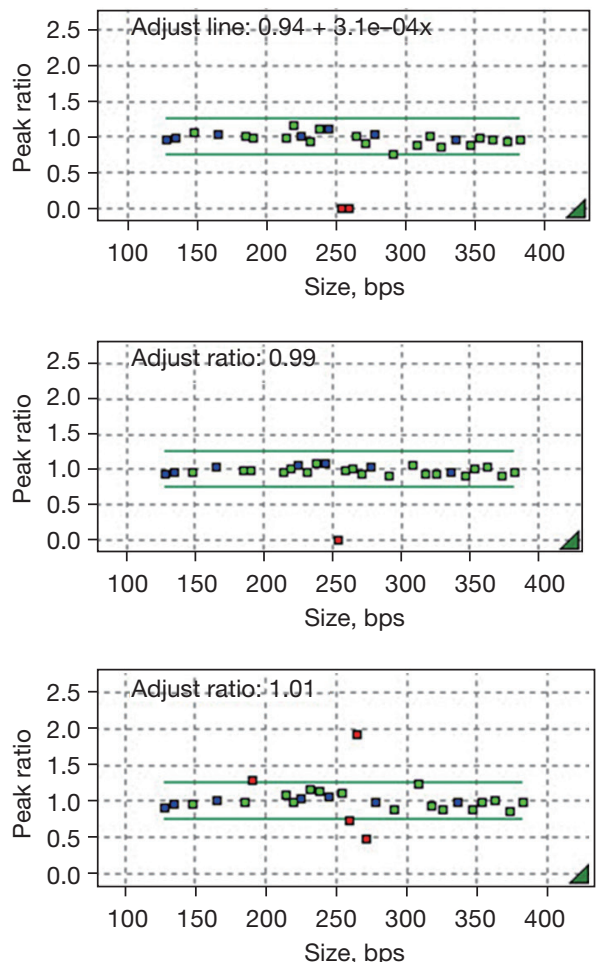

Figure 2 Figure showing the mutations identified in CYP21A2. Sequencing revealed heterozygous mutations (293-13C>G, p.?) in both of his parents, and the patient carried a homozygous mutation.

13 years at a chronological age of 4 years and 6 months. His midparental target height was $173.5 \pm 5 \mathrm{~cm}$, while his actual predicted height was $145 \mathrm{~cm}$ by estimation using the bone age and current height.

He was diagnosed with $\mathrm{CAH}$ based on his clinical features and abnormal test results. He underwent a chromosomal test and was unexpectedly found to have a 47, XXY karyotype; therefore, KS was suspected.

He was then transferred to the clinic of the Department of Endocrinology of Shanghai Children's Hospital. His $\mathrm{CAH}$ diagnosis was confirmed using genetic analysis, which revealed $21 \mathrm{OHD}$ caused by a homozygous mutation in CYP21A2. We also found that the c. 293-13C $>\mathrm{G}$ mutation of CYP21A2 caused abnormal pre-mRNA splicing, resulting in the synthesis of an immature or malfunctioning protein, through orthogonal testing with long-range polymerase chain reaction and multiplex ligation-dependent probe amplification. The results of long Sanger sequencing and multiplex ligation-dependent probe amplification revealed heterozygous nonsense mutations in both the parents (Figure 2). We diagnosed the patient with KS associated with
CAH based on the above mentioned results.

We also supplemented these results after 6 months of initial presentation by measuring the basal $\mathrm{LH}$ and FSH levels, which were 2.12 and $4.49 \mathrm{IU} / \mathrm{L}$, respectively. These values peaked at 10.8 and $9.15 \mathrm{IU} / \mathrm{L}$ after the $\mathrm{LH}$-releasing hormone stimulation test. The serum anti-Müllerian hormone and serum inhibin B levels were $103.6 \mathrm{ng} / \mathrm{mL}$ and $123.46 \mathrm{pg} / \mathrm{mL}$, respectively. The SRY analysis results were positive according to fluorescent in situ hybridization. The increased basal and stimulated gonadotropin levels were consistent with a diagnosis of $\mathrm{CAH}$ and central precocious puberty (CPP).

\section{Treatment and follow-up}

Based on the clinical features and abnormal laboratory examination and genetic analysis results, the patient was diagnosed with $\mathrm{KS}, \mathrm{CAH}$, and CPP. He was treated with hydrocortisone $\left(20 \mathrm{mg} / \mathrm{m}^{2} /\right.$ day $)$ accordingly. The dosage was calculated based on the patient's $17 \mathrm{OHP}$, testosterone, and progesterone levels. 

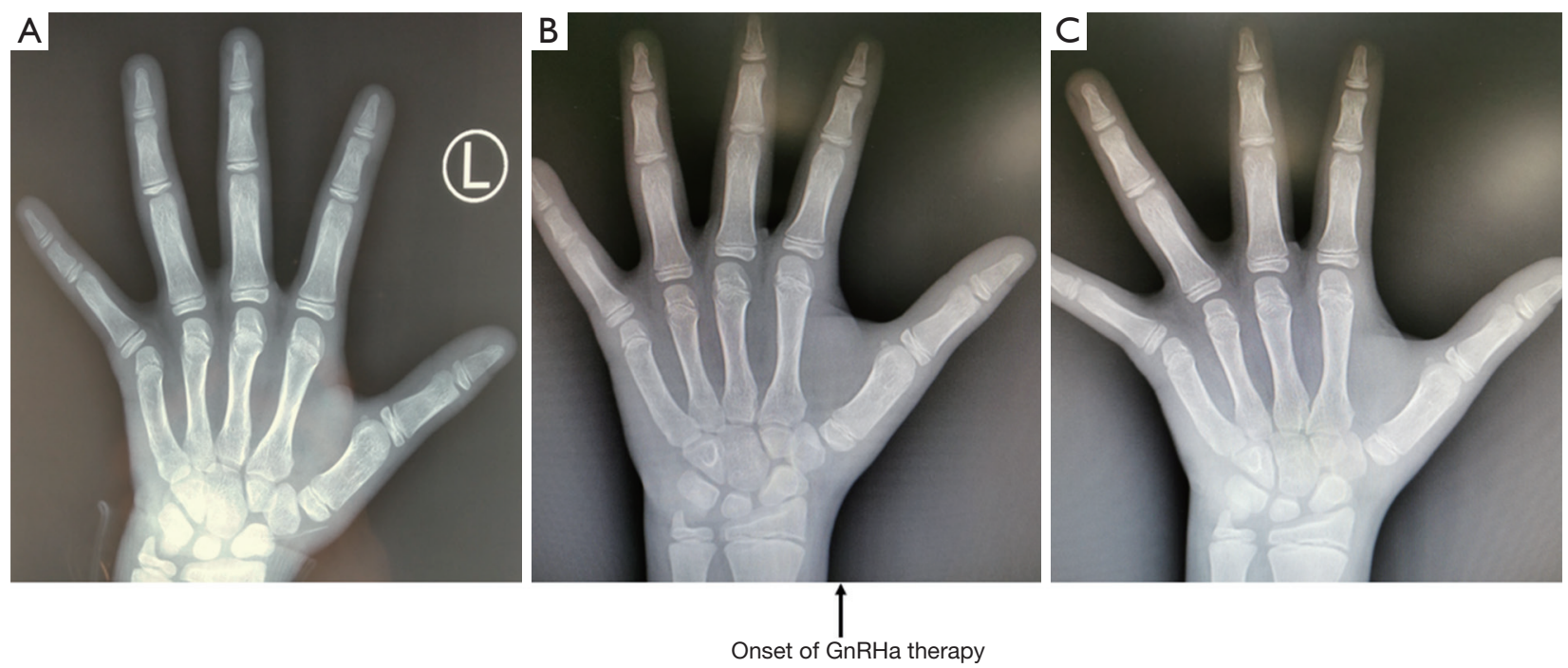

Figure 3 The patient's bone ages at different stages. (A) The patient's bone age was calculated as 13 years at his first visit to the doctor at 4 years and 6 months of age. (B) His bone age was calculated as 13.5 years at when he was 5 years and 6 months of age. (C) His bone age remained the same after GnRHa therapy (13.5 years) when it was measured again at 6 years and 8 months of age. GnRHa, gonadotropinreleasing hormone analog.

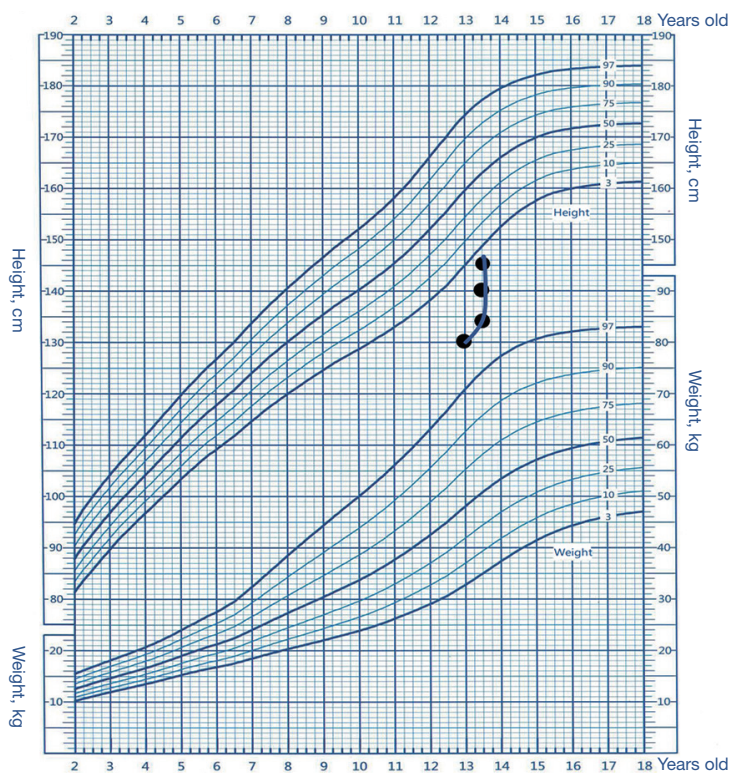

Figure 4 Figure showing the current height of the patient. The $\mathrm{X}$-axis represents his bone age in years and the $\mathrm{Y}$-axis represents his current height in $\mathrm{cm}$.

Due to the combined factors of CAH and CPP, excessive adrenal and testicular androgen levels would have resulted in failure to achieve the target height of $173.5 \mathrm{~cm}$. Finally, the patient was administered gonadotropin-releasing hormone analogue (GnRHa) and recombinant human growth hormone (rhGH) therapies to increase his predicted final height. Compared to the previous bone age (Figure $3 A$ ), we measured the bone age at 13.5 years old at the beginning of the therapies (Figure 3B). Two years after treatment, his bone age remained same as 13.5 years old (Figure 3C), his height had increased by $15.3 \mathrm{~cm}$ (Figure 4), and his sex hormone levels had decreased to the following values: $\mathrm{LH}$, $1.74 \mathrm{IU} / \mathrm{L} ; \mathrm{FSH}, 1.48 \mathrm{IU} / \mathrm{L}$; and testosterone, $0.35 \mathrm{nmol} / \mathrm{L}$ (Figure 5). His predicted adult height was approximately $160 \mathrm{~cm}$ by estimation using the bone age and current height, which is much taller than the estimated height before treatment.

All procedures performed in studies involving human participants were in accordance with the ethical standards of the institutional and/or national research committee(s) and with the Helsinki Declaration (as revised in 2013). Written informed consent was taken from the patient's parent or legal guardian for publication of this case report and accompanying images. A copy of the written consent is available for review by the editorial office of this journal.

\section{Discussion}

$21 \mathrm{OHD}$ is the most common cause of $\mathrm{CAH}$, which is caused by pathogenic mutations in the CYP21A2 

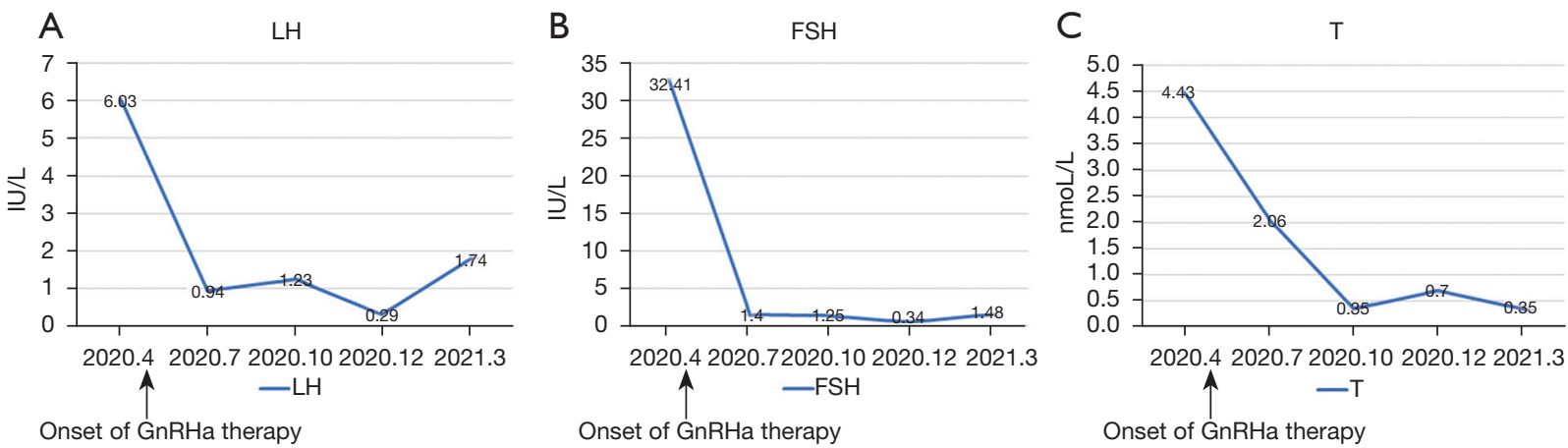

Figure 5 The patient's sex hormone levels decreased after GnRHa therapy. GnRHa, gonadotropin-releasing hormone analog; LH, luteinizing hormone; FSH, follicle stimulating hormone; T, testosterone.

gene (3). Despite having reduced rates of cortisol and/ or aldosterone synthesis, patients with $210 H D$ exhibit increased adrenal androgen levels. The classical pathway to synthesize high levels of testosterone is to convert cholesterol to dehydroepiandrosterone, which in turn is converted to androstenedione and then to testosterone. The substantial conversion of $17 \mathrm{OHP}$ to androstenedione results in excessive testosterone (4). Furthermore, $17 \mathrm{OHP}$ is converted to $5 \alpha$-pregnane-17 $\alpha$-ol-3,20dione, 17-hydroxyallopregnanolone, androsterone, $3 \alpha$-androstanediol, and finally to androgen double hydrogen testosterone (5). Androgens may also arise from the biosynthesis of 11-oxygenated androgens, such as 11-ketotestosterone and 11-ketodihydrotestosterone resulting from the conversion of androstenedione to $11 \beta$-hydroxyandrostenedione (6).

$\mathrm{KS}$ is characterized by the presence of an extra $\mathrm{X}$ chromosome in men, resulting in a 47, XXY karyotype or $(46, X Y) /(47, X X Y)$ mosaicism. KS individuals present with primary testicular insufficiency and Leydig and Sertoli cell dysfunction. Individuals with KS typically start puberty at the appropriate time. Hypogonadism then develops during adolescence. Patients' testes grow to nearly 6-8 $\mathrm{mL}$ before becoming firm and shrunk (2). Serum testosterone levels decrease and causes a feedback-mediated increase in the pituitary secretion of LH and FSH.

In the present study, we describe a rare case of $\mathrm{CAH}$ and $\mathrm{KS}$ occurring simultaneously, the former resulting in excessive testosterone, while the latter causing testosterone insufficiency. We found a total of six case reports on patients with both diseases.

The first case was reported in 1994 (7). The patient was diagnosed with the simple virilizing form of $\mathrm{CAH}$ and
21OHD at birth, and presented with small and firm testes at follow-up. Chromosomal examination confirmed that he had KS and a 47, XXY karyotype. After discontinuing steroid hormone therapy, he exhibited sexual precocity, acceleration of bone age, and premature closure of the epiphyses. He also presented with hypergonadotropic hypogonadism. His testes were only $5 \mathrm{~mL}$ in size, and a testicular biopsy revealed severe hyalinization of the seminiferous tubules and hyperplasia of the Leydig cells. He was treated with dexamethasone, and his final height was $149 \mathrm{~cm}$.

The second case was reported in 2006 (8). The authors reported on a boy whose newborn screening results suggested a CAH diagnosis. His peripheral blood cell karyotype was mosaic 48, XXY, +mar[30]/47, XXY, and he had microcephaly and mild developmental delays in fine and gross motor and language skills. He was treated with hydrocortisone, fludrocortisone, and sodium chloride supplementation.

The third case was reported in 2008 (9). The patient was a 51-year-old man with bilateral mastodynia chest ultrasonography and mammography revealed gynecomastia. Based on the results of an endocrinological study and karyotype analysis, the patient was diagnosed with $\mathrm{CAH}$ (21OHD) and KS (karyotype 47, XXY). Despite having hypergonadotropic hypogonadism, his sexual behavior, including libido, erectile function, and sexual intercourse, was normal. He did not exhibit severe testosterone insufficiency or virilization. A biopsy of his testes revealed atrophied seminiferous tubules and large interstitial cell clusters caused by Leydig cell hyperplasia. The patient was administered cortisone acetate ( $25 \mathrm{mg}$ daily). After 6 months of corticosteroid treatment, his androstenedione 
levels decreased, his sexual desire and frequency of sexual intercourse decreased gradually, and he developed erectile dysfunction. The patient was administered testosterone supplementation therapy, after which he underwent mammary plastic surgery.

The fourth reported case was a boy who was diagnosed with $\mathrm{CAH}$ associated with $3 \beta$-Hydroxysteroid dehydrogenase deficiency at 8 years of age and KS at 9 years of age because he had a 47, XXY karyotype (10). He had a short stature and exhibited premature pubarche at 6 years of age. Upon examination, his bone age was reportedly accelerated, and he was diagnosed with early puberty secondary to adrenal hyperandrogenism. Eventually, he was administered a steroid hormone (rhGH) and an aromatase inhibitor to delay epiphyseal fusion. At his final follow-up at a chronological age of 11 years and 2 months, he exhibited satisfactory growth velocity due to rhGH therapy, as well as Tanner stage 5 pubic hair, $4 \mathrm{~mL}$ testes, and a Tanner 3 phallus. His bone age was 12 years and 6 months at that time.

The fifth patient was a boy suspected to have $\mathrm{CAH}$ (21OHD) at 2 years of age (11). He presented with advanced bone age, precocious pubarche, and acne. His development process was normal; however, his puberty development was delayed and he had a small testicular volume of 3-4 mL at the age of 16 years. His pubic hair had developed and his penis had reached pubertal length. At the chronological age of 16 years, his bone age was delayed by 3 years, and blood examination revealed low serum testosterone levels. He presented with slightly increased gonadotropin levels and small-volume testes, but no signs of erectile dysfunction, at the age of 18 . Semen analysis revealed that he had no sperm, and his karyotype was 47, $\mathrm{XXY}$, by which he was diagnosed with KS. He was treated with oral hydrocortisone and fludrocortisone acetate with good compliance.

The most recent reported case of CAH combined with KS was published in 2018 (12). The boy was born with penoscrotal hypospadias with bilateral cryptorchidism. At the age of 7 years, he presented with accelerated growth, premature appearance of axillary and pubic hair, progressive blackening of the skin, and progressive enlargement of his penis. He also had a medical history of occasional nausea and diarrhea. He was diagnosed with $\mathrm{CAH}$ (3ß-hydroxysteroid dehydrogenase) based on the results of routine blood tests and gene analysis. The presence of penoscrotal hypospadias with bilateral cryptorchidism led clinicians to perform karyotype analysis, and the results were unexpected: mosaic KS 47, XXY/46, XX (3:1). He was treated with hydrocortisone and fludrocortisone, and orchidopexy was performed. A procedure to treat his hypospadias was planned, and he required androgen replacement due to the development of hypogonadism.

We report the seventh documented case of simultaneous $\mathrm{CAH}$ and KS. These instances are rare, and the point of interest in our case is the particular characteristic of excess androgen due to $\mathrm{CAH}$ combined with androgen deficiency caused by KS. The gonadotropin levels of this patient, including LH and FSH levels, progressively increased after visiting our clinic. We speculated that this was a sign of CPP caused by the activation of the hypothalamic-pituitarygonadal (HPG) axis by androgens, rather than decreased androgen levels, thereby causing a feedback-mediated increase in pituitary secretion.

GnRHa administration can suppress puberty and postpone the premature fusion of the epiphyses in patients with CAH who develop CPP, resulting in an increased estimated final height. However, when these patients also have KS, the question of whether they can be treated with GnRHa arises. Since GnRHa continuously stimulates the pituitary gonadotrophs, resulting in desensitization and reduced LH secretion, as well as that of FSH to a less extent, and the treatment does not target gonadal cells, we obtained informed consent from the patient's guardians to administer GnRHa to treat the patient's advanced bone age. The predicted height of the patient was far below his midparental target height; therefore, we administered rhGH. At the last treatment follow-up, we observed that a combination of GnRHa and rhGH treatment effectively suppressed puberty, delayed acceleration of bone age, and promoted growth. Retrospective studies of cases with CPP and KS that were treated with GnRHa reported that several cases had both idiopathic CPP and KS (13-20). These cases presented with a normal HPG axis, hypogonadism, and residual gonadal function. Thus, these disorders are hypothesized to be related to early activation of the HPG axis, and CPP may be related to hypogonadism. However, in our case, CPP was secondary to CAH, unlike the other reasons in previous cases of simultaneous $\mathrm{CPP}$ and $\mathrm{KS}$.

However, the effect of suppressing the HPG axis during childhood on future HPG axis function must be elucidated. In previous cases (9-12), precocious puberty was observed to be a feature of excess androgen mediated by the clinical features of KS. Excessive androgen levels also masked KS-related hypogonadism, such as delay in puberty and reduced serum testosterone levels. When steroid treatment is initiated, the patients may present with 
firm, shrunken testes, rapid and progressive deterioration of sexual activity, and decreased serum testosterone levels (12). However, our patient exhibited no signs of hypogonadism. We notified the patient and his guardian of the possibility of hypogonadism before administering GnRHa to avoid unnecessary misunderstanding. The clinical expression KS associated with CAH (21OHD) may differ between individuals of different age groups, and the clinical response to replacement therapy may be unpredictable. Testosterone replacement therapy may be administered in future cases if the hypogonadal features become significant.

\section{Conclusions}

This is the first reported case of the simultaneous occurrence of KS, CAH, and CPP. The patient was treated with steroid hormones for protopathy caused by $\mathrm{CAH}$ and with GnRHa and rhGH to increase his predicted final height. Excessive androgen levels may temporarily mask the features of KS-related hypogonadism; therefore, the possibility of hypogonadism and KS should be considered in patients with both $\mathrm{CAH}$ and CPP who have firm, relatively small testes, or slightly less excessive androgen levels compared to others with $\mathrm{CAH}$.

\section{Acknowledgments}

Funding: This work was supported by the Shanghai Sailing Program (No. 21YF1438100) and the Youth Scientific Research Project of Shanghai Health Commission (No. 20204Y0468).

\section{Footnotes}

Reporting Checklist: The authors have completed the CARE reporting checklist. Available at https://tp.amegroups.com/ article/view/10.21037/tp-21-442/rc

Peer Review File: Available at https://tp.amegroups.com/ article/view/10.21037/tp-21-442/prf

Conflicts of Interest: All authors have completed the ICMJE uniform disclosure form (available at https://tp.amegroups. com/article/view/10.21037/tp-21-442/coif). The authors have no conflicts of interest to declare.

Ethical Statement: The authors are accountable for all aspects of the work in ensuring that questions related to the accuracy or integrity of any part of the work are appropriately investigated and resolved. All procedures performed in studies involving human participants were in accordance with the ethical standards of the institutional and/or national research committee(s) and with the Helsinki Declaration (as revised in 2013). Written informed consent was taken from the patient's parent or legal guardian for publication of this case report and accompanying images. A copy of the written consent is available for review by the editorial office of this journal.

Open Access Statement: This is an Open Access article distributed in accordance with the Creative Commons Attribution-NonCommercial-NoDerivs 4.0 International License (CC BY-NC-ND 4.0), which permits the noncommercial replication and distribution of the article with the strict proviso that no changes or edits are made and the original work is properly cited (including links to both the formal publication through the relevant DOI and the license). See: https://creativecommons.org/licenses/by-nc-nd/4.0/.

\section{References}

1. New MI. Inborn errors of adrenal steroidogenesis. Mol Cell Endocrinol 2003;211:75-83.

2. Kanakis GA, Nieschlag E. Klinefelter syndrome: more than hypogonadism. Metabolism 2018;86:135-44.

3. Pignatelli D, Pereira SS, Pasquali R. Androgens in Congenital Adrenal Hyperplasia. Front Horm Res 2019;53:65-76.

4. Miller WL. MECHANISMS IN ENDOCRINOLOGY: Rare defects in adrenal steroidogenesis. Eur J Endocrinol 2018;179:R125-41.

5. Kamrath C, Hochberg Z, Hartmann MF, et al. Increased activation of the alternative "backdoor" pathway in patients with 21-hydroxylase deficiency: evidence from urinary steroid hormone analysis. J Clin Endocrinol Metab 2012;97:E367-75.

6. Pretorius E, Arlt W, Storbeck KH. A new dawn for androgens: Novel lessons from 11-oxygenated C19 steroids. Mol Cell Endocrinol 2017;441:76-85.

7. Yamaguchi T, Abe H, Kuwano T, et al. Congenital adrenal hyperplasia with 47, XXY Klinefelter syndrome. Exp Clin Endocrinol 1994;102:348-50.

8. Parker EA, Hovanes K, Germak J, et al. Maternal 21-hydroxylase deficiency and uniparental isodisomy of chromosome 6 and $\mathrm{X}$ results in a child with 21-hydroxylase deficiency and Klinefelter syndrome. Am J Med Genet A 
2006;140:2236-40.

9. Balestrieri A, Zirilli L, Madeo B, et al. 21-hydroxylase deficiency and klinefelter syndrome in an adult man: striking a balance between androgen excess and insufficiency. J Androl 2008;29:605-9.

10. Gortakowski M, Conroy R, Aguiar L, et al. Premature pubarche in a child with abnormal $3 \beta$-hydroxysteroid dehydrogenase function and Klinefelter syndrome: the intriguing relationship between androgen deficiency and excess. Clin Case Rep 2016;5:57-60.

11. Zanella G, Tornese G, Mascheroni E, et al. A Klinefelter boy with congenital adrenal hyperplasia: too much or too little androgens? Ital J Pediatr 2018;44:43.

12. Shehab MA, Mahmood T, Hasanat MA, et al. A rare variety of congenital adrenal hyperplasia with mosaic Klinefelter syndrome: a unique combination presenting with ambiguous genitalia and sexual precocity Endocrinol Diabetes Metab Case Rep 2018;2018:18-0108.

13. Bertelloni S, Battini R, Baroncelli GI, et al. Central precocious puberty in 48,XXYY Klinefelter syndrome variant. J Pediatr Endocrinol Metab 1999;12:459-65.

14. Bebb GG, Grannis FW Jr, Paz IB, et al. Mediastinal germ cell tumor in a child with precocious puberty and Klinefelter syndrome. Ann Thorac Surg 1998;66:547-8.

Cite this article as: $\mathrm{Li} \mathrm{Y,} \mathrm{Zhang} \mathrm{T,} \mathrm{Li} \mathrm{P.} \mathrm{Treatment} \mathrm{of}$ congenital adrenal hyperplasia and Klinefelter Syndrome with central precocious puberty: a case report. Transl Pediatr 2022;11(2):298-305. doi: 10.21037/tp-21-442
15. Völkl TM, Langer T, Aigner T, et al. Klinefelter syndrome and mediastinal germ cell tumors. Am J Med Genet A 2006;140:471-81.

16. Chen CK, Chang YL, Jou ST, et al. Treatment of mediastinal immature teratoma in a child with precocious puberty and Klinefelter's syndrome. Ann Thorac Surg 2006;82:1906-8.

17. Lin CM, Lee CT, Tung YC, et al. Endocrine dysfunction in Taiwanese children with human chorionic gonadotropin-secreting germ cell tumors. J Formos Med Assoc 2014;113:102-5.

18. von Mühlendahl KE, Heinrich U. Sexual precocity in Klinefelter syndrome: report on two new cases with idiopathic central precocious puberty. Eur J Pediatr 1994;153:322-4.

19. Bertelloni S, Baroncelli GI, Battini R, et al. Central precocious puberty in Klinefelter syndrome: a case report with longitudinal follow-up of growth pattern. Am J Med Genet 1996;65:52-5.

20. Gonzales-Ellis BA, Pingul MM, Reddy S, et al. Growth hormone deficiency and central precocious puberty in Klinefelter syndrome: report of a case and review of KIGS database. J Pediatr Endocrinol Metab 2013;26:361-4. 